\title{
Clinical trial registration: a statement from the International Committee of Medical Journal Editors
}

\author{
Catherine De Angelis, Jeffrey M. Drazen, Frank A. Frizelle, Charlotte Haug, John Hoey, \\ Richard Horton, Sheldon Kotzin, Christine Laine, Ana Marusic, A. John P.M. Overbeke, \\ Torben V. Schroeder, Hal C. Sox, Martin B. Van Der Weyden
}

A ltruism and trust lie at the heart of research on human subjects. Altruistic individuals volunteer for research because they trust that their participation will contribute to improved health for others and that researchers will minimize risks to participants. In return for the altruism and trust that make clinical research possible, the research enterprise has an obligation to conduct research ethically and to report it honestly. Honest reporting begins with revealing the existence of all clinical studies, even those that reflect unfavourably on a research sponsor's product.

Unfortunately, selective reporting of trials does occur, and it distorts the body of evidence available for clinical decision-making. Researchers (and journal editors) are generally most enthusiastic about the publication of trials that show either a large effect of a new treatment (positive trials) or equivalence of 2 approaches to treatment (noninferiority trials). Researchers (and journals) typically are less excited about trials that show that a new treatment is inferior to standard treatment (negative trials) and even less interested in trials that are neither clearly positive nor clearly negative, since inconclusive trials will not in themselves change practice. Irrespective of their scientific interest, trial results that place financial interests at risk are particularly likely to remain unpublished and hidden from public view. The interests of the sponsor or authors notwithstanding, anyone should be able to learn of any trial's existence and its important characteristics.

The case against selective reporting is particularly compelling for research that tests interventions that could enter mainstream clinical practice. Rather than a single trial, it is usually a body of evidence, consisting of many studies, that changes medical practice. When research sponsors or investigators conceal the presence of selected trials, these studies cannot influence the thinking of patients, clinicians, other researchers, and experts who write practice guidelines or decide on insurance-coverage policy. If all trials are registered in a public repository at their inception, every trial's existence is part of the public record and the many stakeholders in clinical research can explore the full range of clinical evidence. We are far from this ideal at present, since trial registration is largely voluntary, registry data sets and public access to them vary, and registries contain only a small proportion of trials. In this editorial, published simul- taneously in all member journals, the International Committee of Medical Journal Editors (ICMJE) proposes comprehensive trials registration as a solution to the problem of selective awareness and announces that all $11 \mathrm{ICMJE}$ member journals will adopt a trials-registration policy to promote this goal.

The ICMJE member journals will require, as a condition of consideration for publication, registration in a public trials registry. Trials must register at or before the onset of patient enrollment. This policy applies to any clinical trial starting enrollment after July 1, 2005. For trials that began enrollment before this date, the ICMJE member journals will require registration by Sept. 13, 2005, before considering the trial for publication. We speak only for ourselves, but we encourage editors of other biomedical journals to adopt similar policies. For this purpose, the ICMJE defines a clinical trial as any research project that prospectively assigns human subjects to intervention or comparison groups to study the cause-and-effect relationship between a medical intervention and a health outcome. Studies designed for other purposes, such as to study pharmacokinetics or major toxicity (e.g., phase I trials), would be exempt.

The ICMJE does not advocate one particular registry, but its member journals will require authors to register their trial in a registry that meets several criteria. The registry must be accessible to the public at no charge. It must be open to all prospective registrants and managed by a not-for-profit organization. There must be a mechanism to ensure the validity of the registration data, and the registry should be electronically searchable. An acceptable registry must include at minimum the following information: a unique identifying number, a statement of the intervention (or interventions) and comparison (or comparisons) studied, a statement of the study hypothesis, definitions of the primary and secondary outcome measures, eligibility criteria, key trial dates (registration date, anticipated or actual start date, anticipated or actual date of last follow-up, planned or actual date of closure to data entry, and date trial data considered complete), target number of subjects, funding source, and contact information for the principal investigator. To our knowledge, at present, only www.clinicaltrials.gov, sponsored by the US National Library of Medicine, meets these requirements; 
there may be other registries, now or in the future, that meet all these requirements.

Registration is only part of the means to an end; that end is full transparency with respect to performance and reporting of clinical trials. Research sponsors may argue that public registration of clinical trials will result in unnecessary bureaucratic delays and destroy their competitive edge by allowing competitors full access to their research plans. We argue that enhanced public confidence in the research enterprise will compensate for the costs of full disclosure. Patients who volunteer to participate in clinical trials deserve to know that their contribution to improving human health will be available to inform health care decisions. The knowledge made possible by their collective altruism must be accessible to everyone. Required trial registration will advance this goal.
This document is not covered by copyright and may be copied or reprinted without permission.

All authors are members of the International Committee of Medical Journal Editors: Catherine De Angelis, Editor-in-Chief, $7 A M A$; Jeffrey M. Drazen, Editor-inChief, New England fournal of Medicine; Frank A. Frizelle, Editor, The New Zealand Medical fournal; Charlotte Haug, Editor-in-Chief, Norwegian Medical Fournal; John Hoey, Editor, CMA7; Richard Horton, Editor, The Lancet; Sheldon Kotzin, Executive Editor, MEDLINE, National Library of Medicine; Christine Laine, Senior Deputy Editor, Annals of Internal Medicine; Ana Marusic, Editor, Croatian Medical Fournal; A. John P.M. Overbeke, Executive Editor, Nederlands, Tijdscbrift voor Geneeskunde (Dutch Fournal of Medicine); Torben V. Schroeder, Editor, Fournal of the Danish Medical Association; Hal C. Sox, Editor, Annals of Internal Medicine; Martin B. Van Der Weyden, Editor, The Medical Fournal of Australia.

Competing interests: None declared.

Correspondence to: John Hoey, Editor, CMAJ, 1867 Alta

Vista Dr., Ottawa ON K1G 3Y6; fax 613 565-5471;

john.hoey@cma.ca

\section{CMAJ's Editorial Fellowship}

The CMAJ EDITORIAL FeLlOWSHIP, launched in 1998, provides an exciting opportunity for physicians early in their training to discover the inner workings of a leading medical journal. Applications are invited from recent medical graduates and residents who are interested in obtaining a rich experience in medical writing, editing and publishing. The fellow participates in all aspects of journal production, ranging from deciding which manuscripts to publish and working with authors to soliciting commentaries and review articles. Fellows are also expected to write extensively and are encouraged to develop theme issues, series or other journal innovations.

The position is full time for one year and is based at CMAJ's offices in Ottawa. The salary is based on the equivalent residency remuneration in Ontario.

The next round of applications is for the 2005 fellowship, which begins July 1,2005 . The application deadline is December 15, 2004.

For more information, please contact Dr. John Hoey, Editor, at john.hoey@cma.ca.

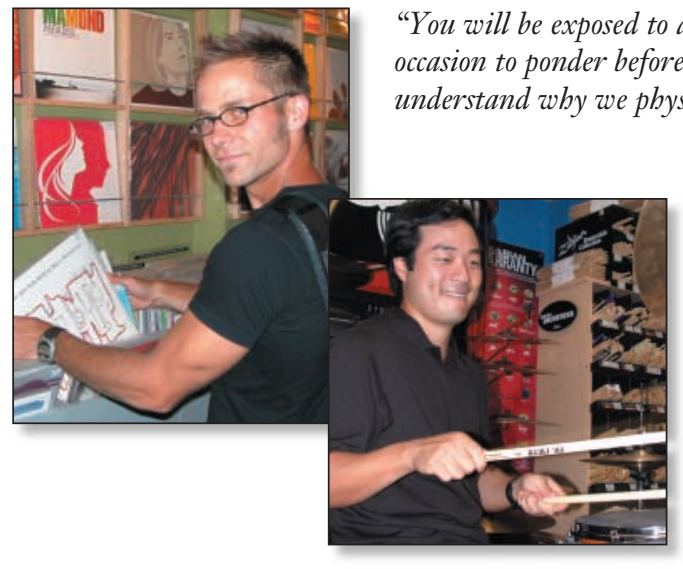

"You will be exposed to aspects of medicine that you never had occasion to ponder before. And, perhaps, you will better understand why we physicians do what we do." — James Maskalyk, fellow 2002

"The fellowship is an amazing opportunity to develop new skills and learn what it means to be an editor. Prepare yourself for an exciting year as you watch new developments in modern medicine unfold before your eyes and help shape how physicians interpret them." 